\title{
Effects of marital status on survival of hepatocellular carcinoma by race/ethnicity and gender
}

This article was published in the following Dove Press journal: Cancer Management and Research

\section{Wenrui Wu ${ }^{1,2}$ \\ Daiqiong Fang ${ }^{1,2}$ \\ Ding Shi ${ }^{1,2}$ \\ Xiaoyuan Bian ${ }^{1,2}$ \\ Lanjuan $\mathrm{Li}^{1,2}$}

'State Key Laboratory for Diagnosis and Treatment of Infectious Diseases, The First Affiliated Hospital, School of Medicine, Zhejiang University, ${ }^{2}$ Collaborative Innovation Center for Diagnosis and Treatment of Infectious Diseases, Hangzhou, People's Republic of China
Correspondence: Lanjuan $\mathrm{Li}$ State Key Laboratory for Diagnosis and Treatment of Infectious Disease, The First Affiliated Hospital, School of Medicine, Zhejiang University, No 79, Qingchun Road, Hangzhou 310003 ,

Zhejiang Province, People's Republic of China

Tel $+8657 \mid 87236458$

Fax +8657187236459

Email lji@@zju.edu.cn
Purpose: It is well demonstrated that being married is associated with a better prognosis in multiple types of cancer. However, whether the protective effect of marital status varied across race/ethnicity and gender in patients with hepatocellular carcinoma remains unclear. Therefore, we aimed to evaluate the roles of race/ethnicity and gender in this relationship.

Patients and methods: We identified eligible patients from Surveillance, Epidemiology and End Results (SEER) database during 2004-2012. Overall and cancer-specific survival differences across marital status were compared by Kaplan-Meier curves. We also estimated crude hazard ratios (CHRs) and adjusted hazard ratios (AHRs) with 95\% confidence intervals (CIs) for marital status associated with survival by race/ethnicity and gender in Cox proportional hazard models. Results: A total of 12,168 eligible patients diagnosed with hepatocellular carcinoma were included. We observed that married status was an independent protective prognostic factor for overall and cancer-specific survival. In stratified analyses by race/ethnicity, the AHR of overall mortality (unmarried vs married) was highest for Hispanic (AHR =1.25, 95\% CI, 1.13-1.39; $P<0.001$ ) and lowest for Asian or Pacific Islander (AHR $=1.13 ; 95 \% \mathrm{CI}, 1.00-1.28 ; P=0.042$ ). Stratified by gender, the AHR was higher in males $(\mathrm{AHR}=1.27 ; 95 \% \mathrm{CI}, 1.20-1.33 ; P<0.001)$. Conclusion: We demonstrated that married patients obtained better survival advantages. Race/ ethnicity and gender could influence the magnitude of associations between marital status and risk of mortality.

Keywords: primary hepatocellular carcinoma, SEER, being married, race, gender, prognosis

\section{Introduction}

Hepatocellular carcinoma (HCC) is the fifth frequently diagnosed malignancy for males and the ninth for females worldwide. ${ }^{1,2}$ Although the incidence of liver cancer is less frequent than that of breast and colorectal cancers, it is the second cause of cancer-related death and estimated to account for $\sim 745,000$ deaths in 2012. ${ }^{1}$ During the past few decades, several advanced therapies including systemic chemotherapy and radiofrequency ablation have shown the modest improvement in overall survival. ${ }^{3-5}$ Despite those achievements, the prognosis of HCC still remained dismal with an overall 1-year survival rate of $<50 \% .{ }^{6}$ Considering high mortality and poor prognosis of $\mathrm{HCC}$, it is still urgent to reduce the risk of mortality associated with HCC.

Recently, results from considerable literature have demonstrated that married patients have favorable survival outcomes compared to the unmarried in various cancer types, such as breast, colorectal, pancreatic, gastric, and prostate cancers. ${ }^{7-14}$ This interesting phenomenon raised great public concerns. It is postulated that the survival 
benefits of marriage are associated with earlier cancer detection and receipt of definitive treatment. ${ }^{15-19}$ Moreover, better economic status and social support contribute to lower cancer mortality in married patients. Previously published articles also indicated that marital status was considered as a prognostic factor of better survival in liver cancer. ${ }^{19,20}$ Less well investigated, however, is the influence of race/ethnicity and gender in the association between being married and overall prognosis of HCC. Therefore, we performed a populationbased study to fill the gap on racial and gender differences in marriage-associated survival benefits,

\section{Patients and methods}

\section{Patient selection and data extraction}

We obtained data from the Surveillance, Epidemiology, and End Results (SEER) database using the SEER*Stat 8.2.1 software. The SEER collected information from 18 population-based cancer registries from 1973 to 2012 and represented $\sim 30 \%$ of the American population. ${ }^{11}$ We identified first primary hepatocellular carcinoma who were aged $\geq 18$ years at diagnosis between 2004 and 2012. Histological types for HCC were limited to $8,170,8,171,8,172,8,173$,
8,174 , and 8,175 according to the International Classification of Diseases for Oncology-3 (ICD-O-3). We excluded cases diagnosed by death certificates or autopsy, or with unknown information about follow-up time, marital status, stage, and grade. We classified marital status into four groups: married, divorced/separated, widowed, and single at the time of diagnosis. Due to the similar survival disadvantages of being unmarried (divorced, separated, widowed, and single), we clustered those together as the unmarried group in further analysis. We defined race/ethnicity as non-Hispanic white (NHW), Black, Hispanic, and Asian or Pacific Islander (API). Demographic and clinical information about gender, age, histology, grade, stage, and definite therapies was extracted from the SEER database. The data accessed from SEER are freely available and do not require approval from an institutional review board or ethics committee. No personal identifying information was used in the current study; therefore, we did not require any informed consent.

\section{Statistical analysis}

Chi-square test was conducted to compare clinical characteristics with different marital statuses among hepatocellular

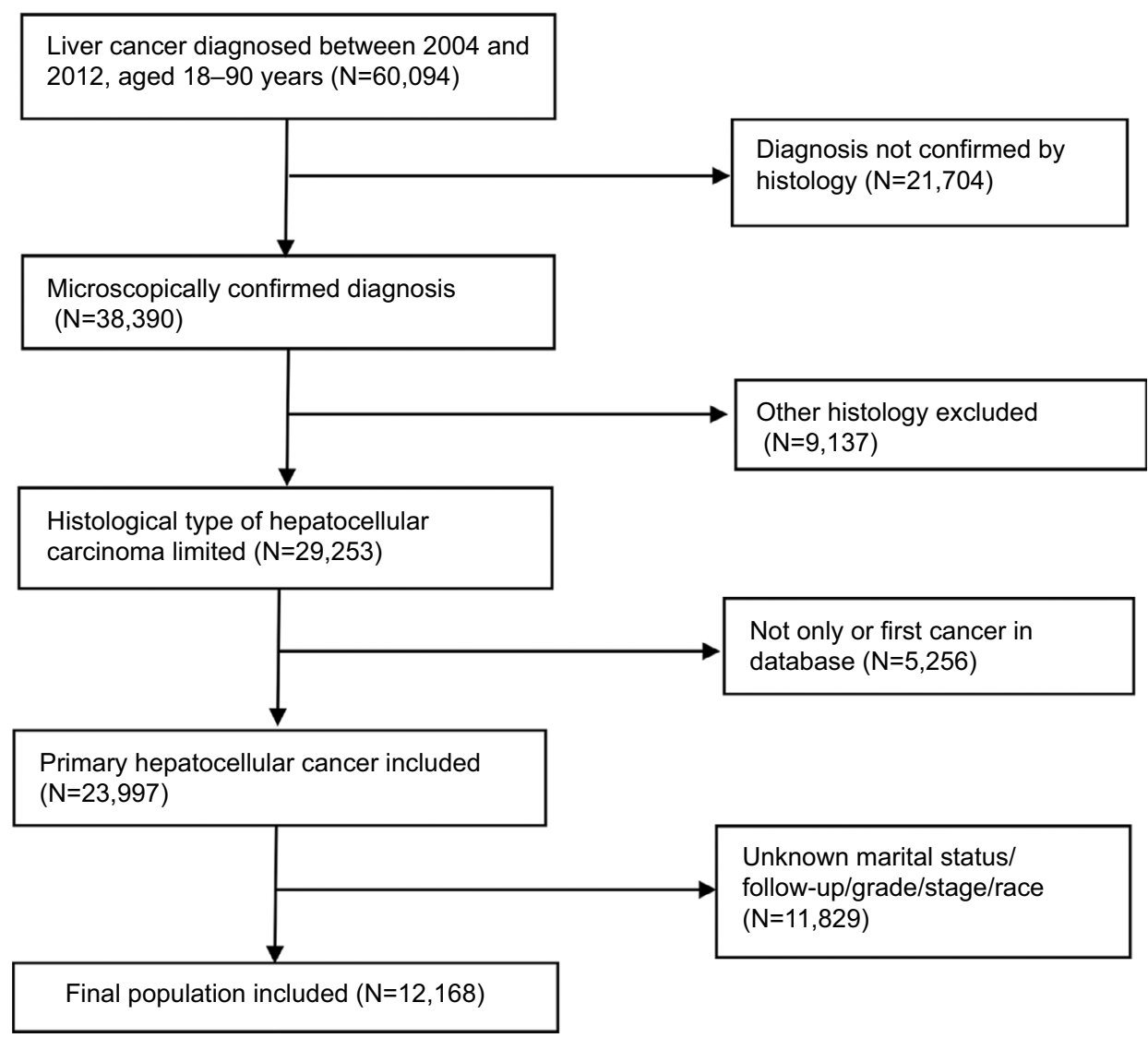

Figure I Flowchart for included patients from the Surveillance, Epidemiology, and End Results database. 
carcinoma. Kaplan-Meier curves and log-rank tests were adopted to compare survival difference in relation to marital status. Multivariable Cox proportional hazards regressions were conducted to estimate hazard ratios (HRs) and 95\% confidence intervals (CIs) for overall and cancer-specific survival among different marital statuses. Furthermore, we conducted analyses to explore advantages of being married by race and gender. All analyses were two sided, and a $P$-value of $<0.05$ indicated statistically significant. All statistical analyses were performed using the IBM SPSS Statistics, Version 20.0, and figures were created using the GraphPad Prism software (GraphPad Software, Inc., La Jolla, CA, USA).

\section{Results}

The cohort totally included 12,168 eligible cases of HCC during 2004-2012. The detailed flowchart of selection is shown in Figure 1. As shown in Table 1, there were 9,355
(76.9\%) males and 2,813 (23.1\%) females. Among included individuals, 7,076 (58.2\%) patients were married, 1,645 (13.5\%) patients were divorced/separated, $1,157(9.5 \%)$ patients were widowed, and 2,290 (18.8\%) patients were single at the diagnosis (Table 1). The married rate was low in female and Black patients, and the rate decreased with the year from 2004 to 2012. Compared to unmarried groups, married patients received more surgery and radiation. In males, the percentages of unmarried patients were $39.3 \%$ for NHWs, $58.3 \%$ for Blacks, $37.7 \%$ for Hispanics, and $20.1 \%$ for APIs (Table 2). In females, the proportions were $52.6 \%$, $74.6 \%, 58.1 \%$, and $40.4 \%$, respectively (Table 3 ).

As shown in Figure 2, the significant difference of overall and cancer-specific mortality was observed between married groups and unmarried groups (divorced/separated, widowed, and single) (both log-rank test $P<0.0001$ ). In multivariate Cox regression models, unmarried status was associated

Table I Baseline clinicopathological characteristics of patients with hepatocellular carcinoma in SEER database

\begin{tabular}{|c|c|c|c|c|c|c|}
\hline Characteristics & Total & Married (\%) & Divorced/separated (\%) & Widowed (\%) & Single (\%) & $P$-value \\
\hline Overall & 12,168 & $7,076(58.2)$ & $1,645(13.5)$ & $\mathrm{I}, \mathrm{I} 57(9.5)$ & $2,290(18.8)$ & \\
\hline Age (years) & & & & & & $<0.001$ \\
\hline$<60$ & 5,249 & $2,891(55.1)$ & $806(15.4)$ & $116(2.2)$ & $1,436(27.4)$ & \\
\hline $60-79$ & 5,914 & $3,653(61.8)$ & $792(13.4)$ & $689(11.7)$ & $780(13.2)$ & \\
\hline$\geq 80$ & 1,005 & $532(52.9)$ & $47(4.7)$ & $352(35.0)$ & $74(7.4)$ & \\
\hline Gender & & & & & & $<0.001$ \\
\hline Male & 9,355 & $5,790(61.9)$ & $1,262(13.5)$ & 491 (5.2) & $1,812(19.4)$ & \\
\hline Female & 2,813 & $\mathrm{I}, 286(45.7)$ & $383(13.6)$ & $666(23.7)$ & $478(17.0)$ & \\
\hline Year & & & & & & $<0.001$ \\
\hline 2004-2006 & 3,540 & $2,143(60.5)$ & $474(13.4)$ & $294(8.3)$ & $629(17.8)$ & \\
\hline $2007-2009$ & $4,|7|$ & $2,402(57.6)$ & $586(14.0)$ & $437(10.5)$ & $746(17.9)$ & \\
\hline $2010-2012$ & 4,457 & $2,531(56.8)$ & $585(13.1)$ & $426(9.6)$ & $915(20.5)$ & \\
\hline Race & & & & & & $<0.001$ \\
\hline Non-Hispanic white & 6,067 & $3,507(57.8)$ & 902 (I4.9) & $636(10.5)$ & $1,022(16.8)$ & \\
\hline Black & 1,680 & $636(37.9)$ & 291 (17.3) & $137(8.2)$ & $616(36.7)$ & \\
\hline Hispanic & 2,146 & $\mathrm{I}, 230(57.3)$ & $307(14.3)$ & $186(8.7)$ & 423 (19.7) & \\
\hline Asian/Pacific Islander & 2,275 & I,703 (74.9) & $145(6.4)$ & $198(8.7)$ & $229(10.1)$ & \\
\hline Grade & & & & & & 0.508 \\
\hline High & 3,936 & $2,254(57.3)$ & $54 \mid(13.7)$ & $364(9.2)$ & 777 (19.7) & \\
\hline Moderate & 5,250 & $3,098(59.0)$ & $694(13.2)$ & $498(9.5)$ & $960(18.3)$ & \\
\hline Poor & 2,730 & $\mathrm{I}, 588(58.2)$ & $377(13.8)$ & $268(9.8)$ & $497(18.2)$ & \\
\hline Undifferentiation & 252 & $136(54.0)$ & $33(13.1)$ & $27(10.7)$ & $56(22.2)$ & \\
\hline Stage & & & & & & $<0.001$ \\
\hline Localized & 6,942 & $4,106(59.1)$ & $946(13.6)$ & $670(9.7)$ & I,220 (I7.6) & \\
\hline Regional & 3,455 & $2,039(59.0)$ & $463(13.4)$ & $282(8.2)$ & 671 (19.4) & \\
\hline Distant & I,77| & 931 (52.6) & $236(13.3)$ & 205 (II.6) & 399 (22.5) & \\
\hline Surgery & & & & & & $<0.001$ \\
\hline Surgery & $5,27 \mid$ & $3,390(64.3)$ & $654(12.4)$ & $352(6.7)$ & $875(16.6)$ & \\
\hline No surgery & 6,838 & $3,661(53.5)$ & $978(14.3)$ & 795 (II.6) & $\mathrm{I}, 404(20.5)$ & \\
\hline Unknown & 59 & $25(42.4)$ & $13(22.0)$ & $10(16.9)$ & II (I8.6) & \\
\hline Radiation & & & & & & 0.046 \\
\hline Radiation & 616 & $392(63.6)$ & $75(12.2)$ & $50(8.1)$ & $99(16.1)$ & \\
\hline No radiation & $\mathrm{II}, 487$ & $6,650(57.9)$ & $1,560(13.6)$ & $1,096(9.5)$ & $2,181(19.0)$ & \\
\hline Unknown & 65 & $34(52.3)$ & $10(15.4)$ & II (I6.9) & $10(15.4)$ & \\
\hline
\end{tabular}

Abbreviation: SEER, Surveillance, Epidemiology and End Results. 


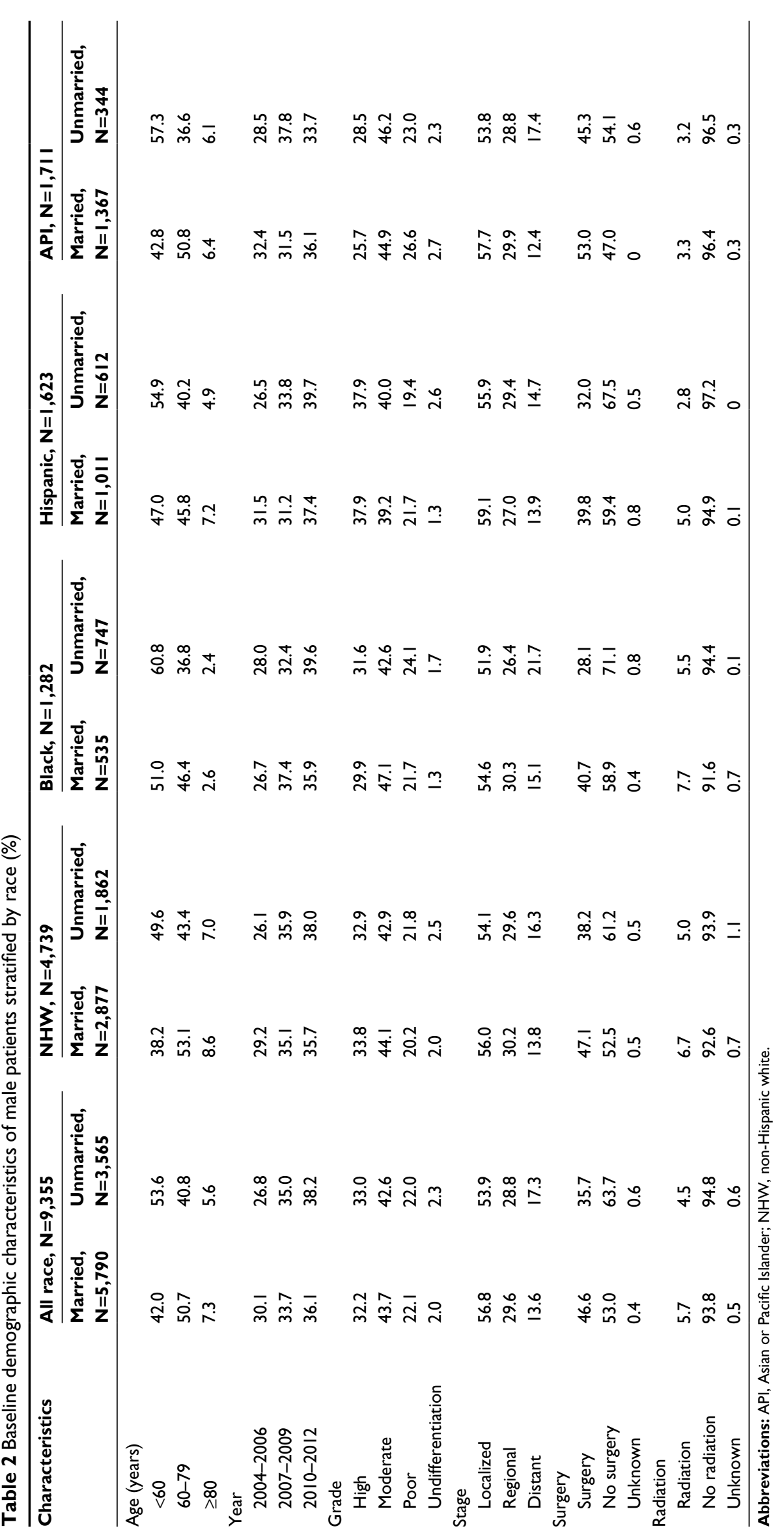




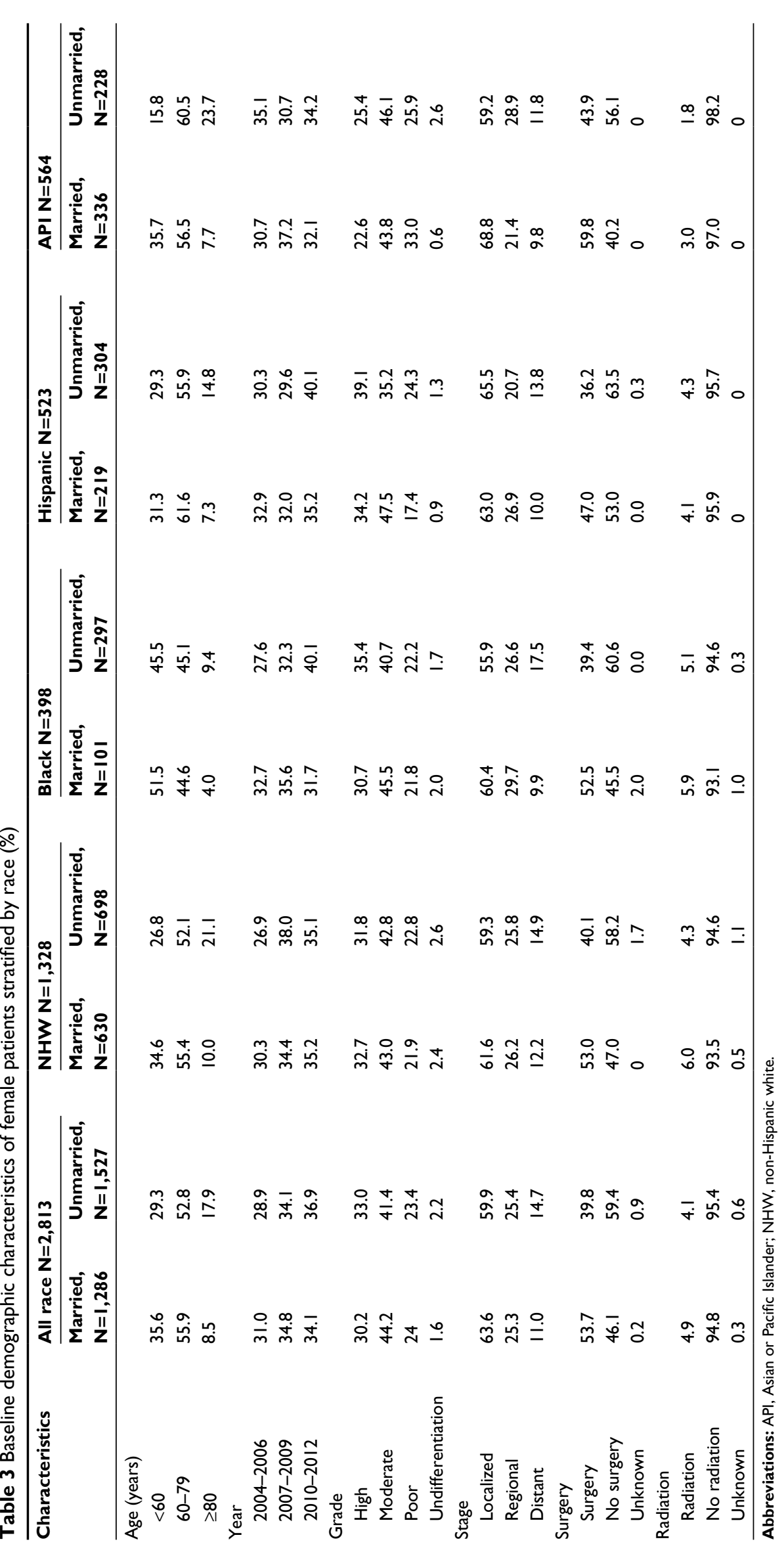


A

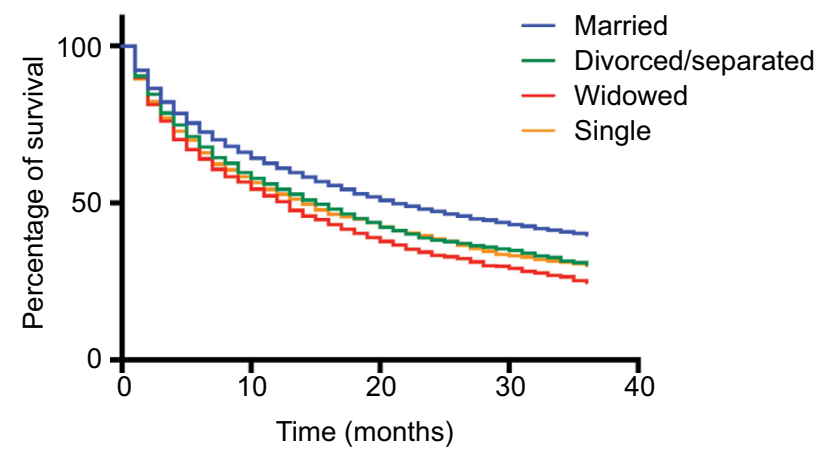

B

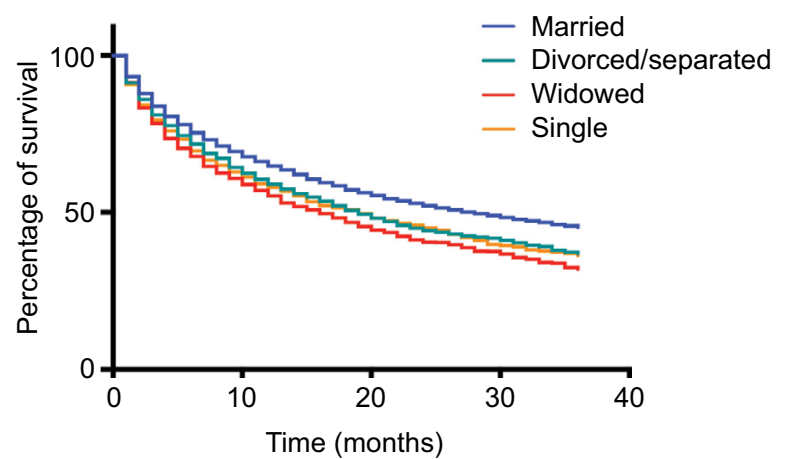

Figure 2 Kaplan-Meier survival curves according to marital status (married, divorced/separated, widowed, and single) in patients with hepatocellular carcinoma. Notes: (A) Overall survival. (B) cancer-specific survival.

Table 4 Univariate and multivariate analyses of OS in patients with HCC

\begin{tabular}{|c|c|c|c|c|}
\hline \multirow[t]{2}{*}{ Variable } & \multicolumn{2}{|l|}{ Univariate } & \multicolumn{2}{|l|}{ Multivariate } \\
\hline & OS HR $(95 \% \mathrm{Cl})$ & $P$-value & OS HR $(95 \% \mathrm{Cl})$ & $P$-value \\
\hline \multicolumn{5}{|l|}{ Age (years) } \\
\hline$<60$ & Reference & & Reference & \\
\hline $60-79$ & $1.22(1.16-1.27)$ & $<0.001$ & $1.19(1.14-1.25)$ & $<0.001$ \\
\hline$\geq 80$ & $1.93(1.79-2.08)$ & $<0.001$ & $1.57(1.46-1.69)$ & $<0.001$ \\
\hline \multicolumn{5}{|l|}{ Gender } \\
\hline Male & Reference & 0.005 & Reference & $<0.001$ \\
\hline Female & $0.93(0.89-0.98)$ & & $0.90(0.86-0.95)$ & \\
\hline \multicolumn{5}{|l|}{ Year } \\
\hline 2004-2006 & Reference & & Reference & \\
\hline $2007-2009$ & $0.95(0.90-1.00)$ & 0.040 & $0.90(0.85-0.94)$ & $<0.001$ \\
\hline $2010-2012$ & $0.88(0.83-0.93)$ & $<0.001$ & $0.82(0.78-0.87)$ & $<0.001$ \\
\hline \multicolumn{5}{|l|}{ Race } \\
\hline Non-Hispanic white & Reference & & Reference & \\
\hline Black & $1.23(1.16-1.31)$ & $<0.001$ & $1.16(1.09-1.23)$ & $<0.001$ \\
\hline Hispanic & $0.94(0.78-1.13)$ & 0.490 & $0.85(0.7 \mathrm{I}-1.02)$ & 0.080 \\
\hline Asian/Pacific Islander & $0.79(0.74-0.83)$ & $<0.001$ & $0.84(0.80-0.89)$ & $<0.001$ \\
\hline \multicolumn{5}{|l|}{ Grade } \\
\hline High & Reference & & Reference & \\
\hline Moderate & $1.04(0.99-1.10)$ & 0.150 & $1.22(1.16-1.28)$ & $<0.001$ \\
\hline Poor & $1.76(1.67-1.87)$ & $<0.001$ & $1.73(1.63-1.83)$ & $<0.001$ \\
\hline Undifferentiation & $1.95(1.70-2.23)$ & $<0.001$ & $1.96(1.71-2.25)$ & $<0.001$ \\
\hline \multicolumn{5}{|l|}{ Stage } \\
\hline Localized & Reference & & Reference & \\
\hline Regional & $2.05(1.95-2.15)$ & $<0.001$ & $1.58(1.50-1.66)$ & $<0.001$ \\
\hline Distant & $4.19(3.95-4.44)$ & $<0.001$ & $2.49(2.35-2.65)$ & $<0.001$ \\
\hline \multicolumn{5}{|l|}{ Marital status } \\
\hline Married & Reference & & Reference & \\
\hline Divorced/separated & $1.25(1.17-1.33)$ & $<0.001$ & $1.20(1.13-1.28)$ & $<0.001$ \\
\hline Widowed & $1.51(1.4|-| .62)$ & $<0.001$ & $1.17(1.09-1.26)$ & $<0.001$ \\
\hline Single & $1.30(1.23-1.37)$ & $<0.001$ & $1.25(1.18-1.32)$ & $<0.001$ \\
\hline \multicolumn{5}{|l|}{ Surgery } \\
\hline Surgery & Reference & & Reference & \\
\hline No surgery & $4.32(4.12-4.53)$ & $<0.001$ & $3.65(3.47-3.84)$ & $<0.001$ \\
\hline Unknown & $4.17(3.19-5.47)$ & $<0.001$ & $3.59(2.74-4.72)$ & $<0.001$ \\
\hline \multicolumn{5}{|l|}{ Radiation } \\
\hline Radiation & Reference & & Reference & \\
\hline No radiation & $0.76(0.69-0.83)$ & $<0.001$ & 1.31 (1.20-1.44) & $<0.001$ \\
\hline Unknown & $1.21(0.92-1.60)$ & 0.170 & $0.92(0.69-1.21)$ & 0.540 \\
\hline
\end{tabular}

Abbreviations: HCC, hepatocellular carcinoma; HR, hazard ratio; OS, overall survival. 
with higher risk of overall mortality (the married as reference, divorced/separated, 1.20, 95\% CI, 1.13-1.28; widowed, 1.17, 95\%CI, 1.09-1.26; single, 1.25, 95\% CI, 1.18-1.32) (Table 4), and similar results were found when cancer-specific survival was analyzed (Table 5). In addition to marital status, other variables such as age, gender, year, race, grade, stage, surgery, and radiation were identified as prognostic factors.

Subsequently, we performed stratified analysis of overall mortality by race/ethnicity and gender. The influence of marital status on overall survival was consistent among race/ ethnicity and gender, though the magnitude of the association varied (Table 6). For both race/ethnicity and gender, unmarried individuals were more likely to be inferior to married individuals in overall survival (Figure 3). For different race/ ethnicity, the HR of being unmarried was the largest in Hispanic (adjusted HR [AHR], 1.25, 95\% CI, 1.13, 1.39), followed by Black (AHR, 1.20, 95\% CI, 1.07, 1.35) and NHW (AHR, 1.19, 95\% CI, 1.12, 1.27), while HR in API was the smallest (AHR 1.13; 95\% CI, 1.00-1.28). As for gender, the influence of being married on prognosis was greater in males (AHR, 1.27; 95\% CI, 1.20-1.33), whereas less effect was observed in females (AHR 1.12; 95\% CI, 1.02-1.23).

Table 5 Univariate and multivariate analyses of cancer-specific survival in patients with HCC

\begin{tabular}{|c|c|c|c|c|}
\hline \multirow[t]{2}{*}{ Variable } & \multicolumn{2}{|l|}{ Univariate } & \multicolumn{2}{|l|}{ Multivariate } \\
\hline & CSS HR (95\% CI) & $P$-value & CSS HR (95\% CI) & $P$-value \\
\hline \multicolumn{5}{|l|}{ Age (years) } \\
\hline$<60$ & Reference & & Reference & \\
\hline $60-79$ & $1.24(1.18-1.30)$ & $<0.001$ & $1.20(1.14-1.26)$ & $<0.001$ \\
\hline$\geq 80$ & 1.86 (I.72-2.02) & $<0.001$ & $1.50(1.38-1.63)$ & $<0.001$ \\
\hline \multicolumn{5}{|l|}{ Gender } \\
\hline Male & Reference & & Reference & \\
\hline Female & $0.94(0.89-0.99)$ & 0.028 & $0.92(0.87-0.98)$ & 0.005 \\
\hline \multicolumn{5}{|l|}{ Year } \\
\hline 2004-2006 & Reference & & Reference & \\
\hline 2007-2009 & $0.94(0.89-0.99)$ & 0.035 & $0.89(0.84-0.94)$ & $<0.001$ \\
\hline $2010-2012$ & $0.88(0.83-0.94)$ & $<0.001$ & $0.83(0.79-0.89)$ & $<0.001$ \\
\hline \multicolumn{5}{|l|}{ Race } \\
\hline Non-Hispanic white & Reference & & Reference & \\
\hline Black & 1.19 (I.II-I.27) & $<0.001$ & 1.10 (1.03-I.18) & 0.006 \\
\hline Hispanic & $\mathrm{I} .02(0.96-\mathrm{I} .09)$ & 0.513 & $0.99(0.93-1.06)$ & 0.792 \\
\hline Asian/Pacific Islander & $0.80(0.75-0.85)$ & $<0.001$ & $0.85(0.80-0.91)$ & $<0.001$ \\
\hline \multicolumn{5}{|l|}{ Grade } \\
\hline High & Reference & & Reference & \\
\hline Moderate & $1.07(1.02-1.13)$ & 0.012 & $1.26(1.20-1.34)$ & $<0.001$ \\
\hline Poor & $1.94(1.83-2.06)$ & $<0.001$ & $1.86(1.75-1.98)$ & $<0.001$ \\
\hline Undifferentiation & $2.04(1.76-2.37)$ & $<0.001$ & $2.00(1.72-2.32)$ & $<0.001$ \\
\hline \multicolumn{5}{|l|}{ Stage } \\
\hline Localized & Reference & & Reference & \\
\hline Regional & $2.26(2.14-2.38)$ & $<0.001$ & 1.70 (I.6I-I.79) & $<0.001$ \\
\hline Distant & $4.80(4.52-5.1 I)$ & $<0.001$ & $2.75(2.57-2.94)$ & $<0.001$ \\
\hline \multicolumn{5}{|l|}{ Marital status } \\
\hline Married & Reference & & Reference & \\
\hline Divorced/separated & I.22 (I.|4-I.3I) & $<0.001$ & I.I8 (I.II-I.27) & $<0.001$ \\
\hline Widowed & I.43 (I.33-I.55) & $<0.001$ & 1.09 (1.00-I.I8) & 0.052 \\
\hline Single & $1.28(1.21-1.36)$ & $<0.001$ & $1.22(1.15-1.30)$ & $<0.001$ \\
\hline \multicolumn{5}{|l|}{ Surgery } \\
\hline Surgery & Reference & & Reference & \\
\hline No surgery & $4.86(4.60-5.13)$ & $<0.001$ & $4.05(3.83-4.29)$ & $<0.001$ \\
\hline Unknown & $4.35(3.21-5.91)$ & $<0.001$ & $3.82(2.8 I-5.20)$ & $<0.001$ \\
\hline \multicolumn{5}{|l|}{ Radiation } \\
\hline Radiation & Reference & & Reference & \\
\hline No radiation & $0.71(0.64-0.78)$ & $<0.001$ & $1.29(1.17-1.42)$ & $<0.001$ \\
\hline Unknown & $\mathrm{I} .07$ (0.79-I.46) & 0.650 & $0.8 \mathrm{I}(0.59-\mathrm{I} .10)$ & 0.170 \\
\hline
\end{tabular}

Abbreviations: CSS, cancer-specific survival; HCC, hepatocellular carcinoma; HR, hazard ratio. 
Table 6 Crude and adjusted HRs for overall survival associated with marital status (unmarried vs married) by gender and race

\begin{tabular}{|c|c|c|c|c|}
\hline Variable & Crude HR & $P$-value & Adjusted HR & $P$-value \\
\hline \multicolumn{5}{|l|}{ Races } \\
\hline All & $1.35(1.29,1.42)$ & $<0.001$ & $1.25(1.19,1.32)$ & $<0.001$ \\
\hline Non-Hispanic white & $1.28(1.20,1.36)$ & $<0.001$ & $1.19(1.12,1.27)$ & $<0.001$ \\
\hline Black & $1.36(1.22,1.53)$ & $<0.001$ & $1.20(1.07,1.35)$ & 0.002 \\
\hline Hispanic & $1.24(1.12,1.36)$ & $<0.001$ & $1.25(1.13,1.39)$ & $<0.001$ \\
\hline Asian or Pacific Islander & $1.24(1.10,1.39)$ & $<0.001$ & $1.13(1.00,1.28)$ & 0.042 \\
\hline \multicolumn{5}{|l|}{ Gender } \\
\hline All & $1.35(1.29,1.42)$ & $<0.001$ & $1.25(1.19,1.32)$ & $<0.001$ \\
\hline Male & $1.35(1.29,1.42)$ & $<0.001$ & $1.27(1.20,1.33)$ & $<0.001$ \\
\hline Female & $1.35(1.23,1.48)$ & $<0.001$ & $1.12(1.02,1.23)$ & 0.016 \\
\hline
\end{tabular}

Abbreviation: $H R$, hazard ratio.

A

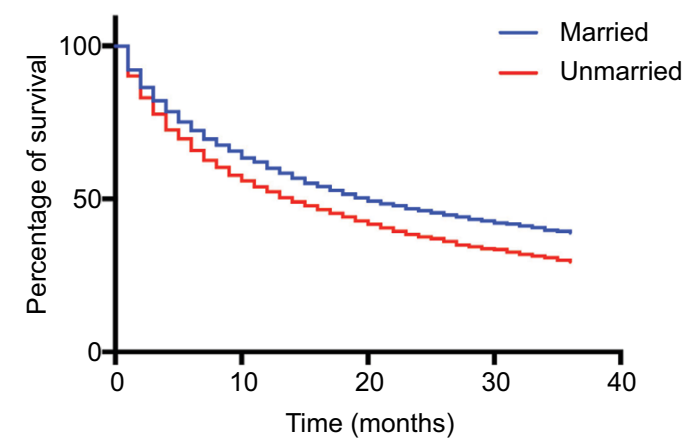

C

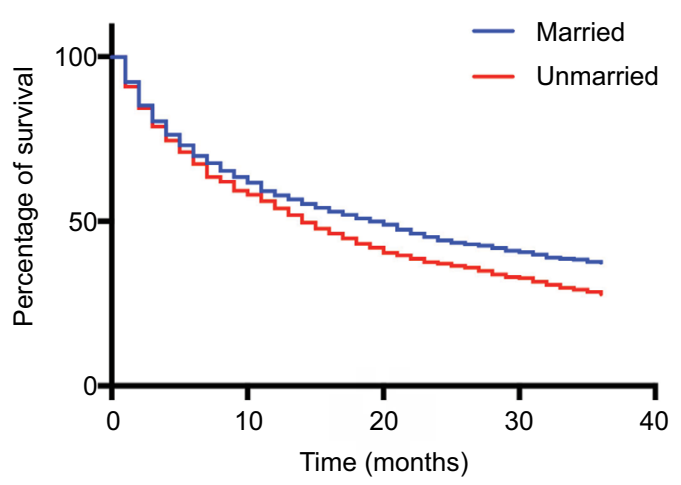

E

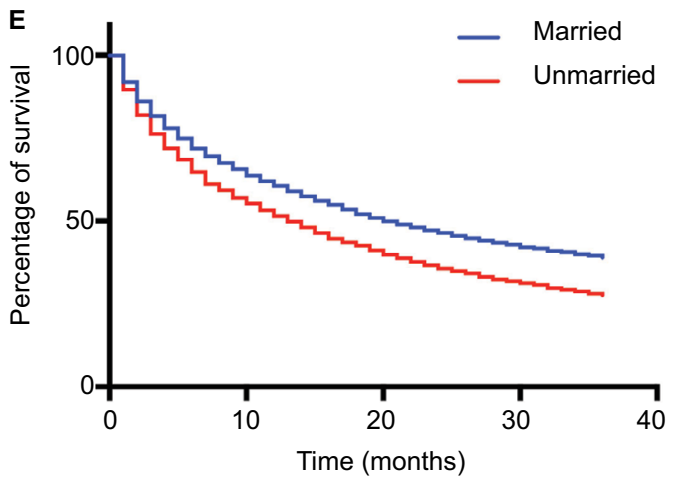

B

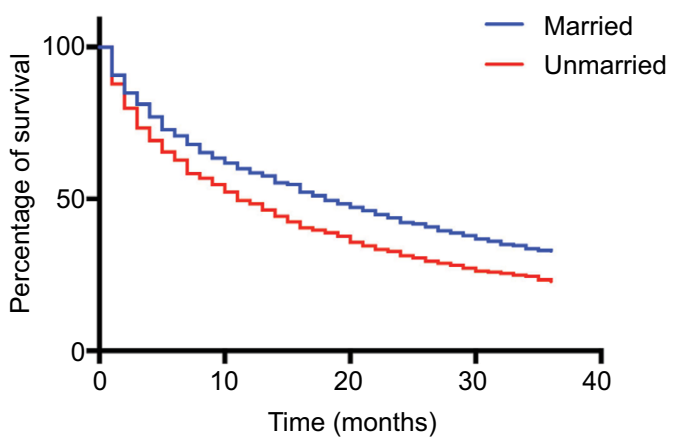

D
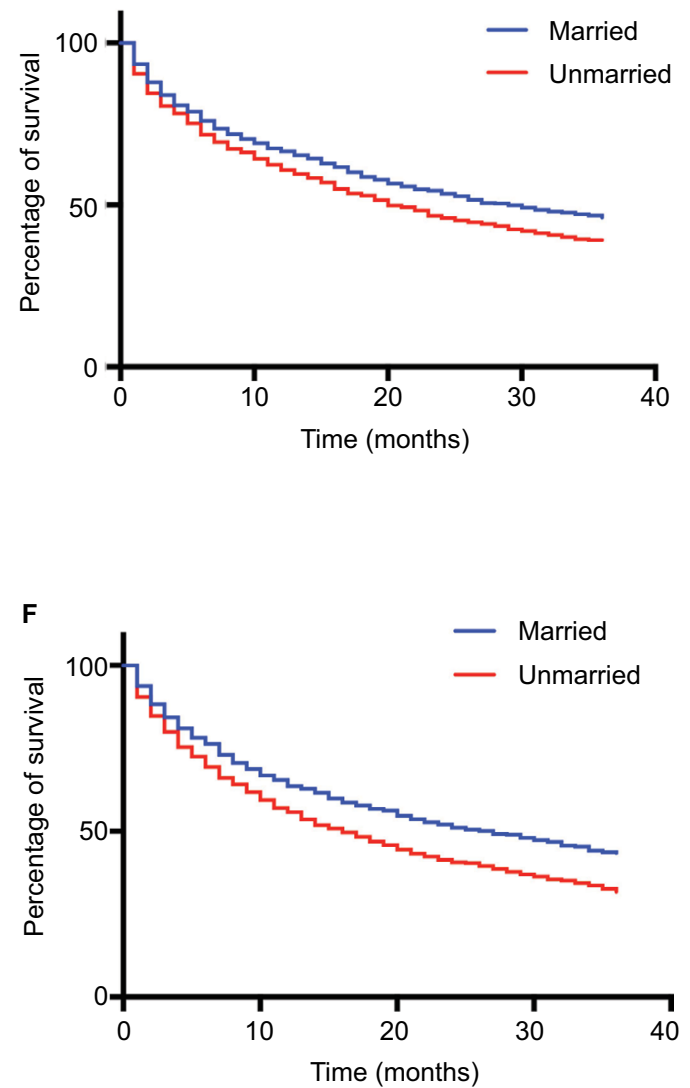

Figure 3 Kaplan-Meier survival curves of overall survival in patients with hepatocellular carcinoma stratified by race/ethnicity and gender. Notes: Percentage of survival for (A) non-Hispanic white, (B) Black, (C) Hispanic, (D) Asian or Pacific Islander, (E) male, (F) female. 


\section{Discussion}

Previous studies had demonstrated that married patients were more likely to possess better prognosis of primary liver cancer. ${ }^{19,20}$ However, to date, survival differences of marital status stratified by race/ethnicity and gender had not been adequately investigated. Therefore, we conducted this population-based study to explore whether race and gender differences could influence the impact of marital status on the prognosis. Our results confirmed previous results that married patients experienced a lower risk of overall and cancer-specific mortality than unmarried patients. Furthermore, we observed variations in the association of being married and prognosis across race/ethnicity and gender. For different races/ethnicities, the association between being married and survival was stronger in Hispanic patients and was weaker in Asian or Pacific Islander patients, which indicated that unmarried Hispanic patients were at the highest risk of mortality in relation to other groups. Compared to males, the impact of being married on overall survival attenuated in females. Although the association between marriage and survival benefits was consistent, it should be noted that the magnitude of this association varied across race/ethnicity and gender. Thus, gender and race/ethnicity might partly explain the influence of marital status on overall survival.

Differences in the relationship between marital status and mortality by race and gender may be attributable to several reasons. First, married patients possessed more financial resources, such as greater income, better employment, and insurance, which ultimately influence the access to early diagnosis and timely medical care. ${ }^{15}$ Second, social supports also contributed to a better prognosis. It was well documented that depression and stress were associated with tumor progression and metastasis. ${ }^{21-24}$ Compared to unmarried counterparts, married patients displayed less distress and depression after diagnosis of cancer because their spouses shared the mental burden and provided them sufficient social support. ${ }^{25,26}$ Goodwin et $\mathrm{al}^{27}$ demonstrated that females with depression experienced a worse survival after a diagnosis of breast cancer. Conversely, breast cancer patients with emotional support enjoyed increased survival. ${ }^{28}$ It has been well documented that stress and depression would impair the immune function and lead to worse prognosis. ${ }^{22,29}$ Moreover, dysregulation of various hormones induced by psychological factors, such as cortisol and norepinephrine, ${ }^{22,30}$ weakens immune systems by suppressing counts and functions of natural killer cells..$^{31,32}$
Inevitably, there were several potential limitations in our study. First, some important information, such as chemotherapy, subsequent therapy, and comorbidities such as HBV infection, was not available in the SEER database. Meanwhile, socioeconomic status of patients also influenced the cancer prognosis. We could not adjust these factors for survival. Second, since marital status was recorded at the diagnosis, we lack data regarding changes in marital status after diagnosis, which may affect the results. Third, as a retrospective research, it was inevitable and liable to introduce some confounders into studies. Given these limitations, the results should be interpreted with caution.

\section{Conclusion}

Notwithstanding these potential limitations, our study demonstrated that being married at the time of diagnosis had a lower risk of mortality across HCC, though this association varied across race/ethnicity and gender. In the consideration of decreased rates of married status, more social support and comprehensive interventions should be given to these populations.

\section{Acknowledgments}

This study was funded by the Key Program of the National Natural Science Foundation of China (No 81330011) and the Science Fund for Creative Research Groups of the National Natural Science Foundation of China (No 81121002). The authors acknowledge the efforts of the SEER Program tumor registries in the creation of the SEER database.

\section{Disclosure}

The authors report no conflicts of interest in this work.

\section{References}

1. Ferlay J, Soerjomataram I, Dikshit R, et al. Cancer incidence and mortality worldwide: sources, methods and major patterns in GLOBOCAN 2012. Int J Cancer. 2015;136(5):E359-E386.

2. Altekruse SF, McGlynn KA, Reichman ME. Hepatocellular carcinoma incidence, mortality, and survival trends in the United States from 1975 to 2005. J Clin Oncol. 2009;27(9):1485-1491.

3. Llovet JM, Bruix J. Systematic review of randomized trials for unresectable hepatocellular carcinoma: chemoembolization improves survival Hepatology. 2003;37(2):429-442.

4. Tiong L, Maddern GJ. Systematic review and meta-analysis of survival and disease recurrence after radiofrequency ablation for hepatocellular carcinoma. Br J Surg. 2011;98(9):1210-1224.

5. Dhanasekaran R, Kooby DA, Staley CA, Kauh JS, Khanna V, Kim HS. Comparison of conventional transarterial chemoembolization (TACE) and chemoembolization with doxorubicin drug eluting beads (DEB) for unresectable hepatocelluar carcinoma (HCC). J Surg Oncol. 2010;101(6):476-480 
6. Shaw JJ, Shah SA. Rising incidence and demographics of hepatocellular carcinoma in the USA: what does it mean? Expert Rev Gastroenterol Hepatol. 2011;5(3):365-370.

7. Baine M, Sahak F, Lin C, Chakraborty S, Lyden E, Batra SK. Marital status and survival in pancreatic cancer patients: a SEER based analysis. PLoS One. 2011;6(6): 21052.

8. Abdollah F, Sun M, Thuret R, et al. The effect of marital status on stage and survival of prostate cancer patients treated with radical prostatectomy: a population-based study. Cancer Causes Control. 2011;22(8):1085-1095.

9. Osborne C, Ostir GV, Du X, Peek MK, Goodwin JS. The influence of marital status on the stage at diagnosis, treatment, and survival of older women with breast cancer. Breast Cancer Res Treat. 2005;93(1):41-47.

10. Qiu M, Yang D, Xu R. Impact of marital status on survival of gastric adenocarcinoma patients: results from the surveillance epidemiology and end results (SEER) database. Sci Rep. 2016;6:21098.

11. Li Q, Gan L, Liang L, Li X, Cai S. The influence of marital status on stage at diagnosis and survival of patients with colorectal cancer. Oncotarget. 2015;6(9):7339-7347.

12. Chen DN, Song CG, Ouyang QW, et al. Differences in breast cancer characteristics and outcomes between Caucasian and Chinese women in the US. Oncotarget. 2015;6(14):12774-12782.

13. Xiao WJ, Zhu Y, Dai B, et al. Conditional survival among patients with adrenal cortical carcinoma determined using a national populationbased surveillance, epidemiology, and end results registry. Oncotarget. 2015;6(42):44955-44962.

14. Shi RL, Chen Q, Yang Z, et al. Marital status independently predicts gastric cancer survival after surgical resection - an analysis of the SEER database. Oncotarget. 2016;7(11):13228-13235.

15. Aizer AA, Chen MH, McCarthy EP, et al. Marital status and survival in patients with cancer. J Clin Oncol. 2013;31(31):3869-3876.

16. Pinquart M, Duberstein PR. Associations of social networks with cancer mortality: a meta-analysis. Crit Rev Oncol Hematol. 2010;75(2):122-137.

17. Wang L, Wilson SE, Stewart DB, Hollenbeak CS. Marital status and colon cancer outcomes in US surveillance, epidemiology and end results registries: does marriage affect cancer survival by gender and stage? Cancer Epidemiol. 2011;35(5):417-422.

18. Wang XD, Qian JJ, Bai DS, Li ZN, Jiang GQ, Yao J. Marital status independently predicts pancreatic cancer survival in patients treated with surgical resection: an analysis of the SEER database. Oncotarget. 2016;7(17):24880-24887.
19. He XK, Lin ZH, Qian Y, Xia D, Jin P, Sun LM. Marital status and survival in patients with primary liver cancer. Oncotarget. 2016;8(39):64954-64963

20. Wu C, Chen P, Qian JJ, et al. Effect of marital status on the survival of patients with hepatocellular carcinoma treated with surgical resection: an analysis of 13,408 patients in the surveillance, epidemiology, and end results (SEER) database. Oncotarget. 2016;7(48): 79442-79452.

21. Powell ND, Tarr AJ, Sheridan JF. Psychosocial stress and inflammation in cancer. Brain Behav Immun. 2013;30(Suppl):S41-S47.

22. Moreno-Smith M, Lutgendorf SK, Sood AK. Impact of stress on cancer metastasis. Future Oncol. 2010;6(12):1863-1881.

23. Reiche EM, Nunes SO, Morimoto HK. Stress, depression, the immune system, and cancer. Lancet Oncol. 2004;5(10):617-625.

24. Tong G, Geng Q, Cheng J, et al. Effects of psycho-behavioral interventions on immune functioning in cancer patients: a systematic review. J Cancer Res Clin Oncol. 2014;140(1):15-33.

25. Cairney J, Boyle M, Offord DR, Racine Y. Stress, social support and depression in single and married mothers. Soc Psychiatry Psychiatr Epidemiol. 2003;38(8):442-449.

26. Goldzweig G, Andritsch E, Hubert A, et al. Psychological distress among male patients and male spouses: what do oncologists need to know? Ann Oncol. 2010;21(4):877-883.

27. Goodwin JS, Zhang DD, Ostir GV. Effect of depression on diagnosis, treatment, and survival of older women with breast cancer. JAm Geriatr Soc. 2004;52(1):106-111.

28. Soler-Vila H, Kasl SV, Jones BA. Prognostic significance of psychosocial factors in African-American and white breast cancer patients: a population-based study. Cancer. 2003;98(6):1299-1308.

29. Garssen B, Goodkin K. On the role of immunological factors as mediators between psychosocial factors and cancer progression. Psychiatry Res. 1999;85(1):51-61.

30. Sood AK, Lutgendorf SK. Stress influences on anoikis. Cancer Prev Res (Phila). 2011;4(4):481-485.

31. Sephton SE, Lush E, Dedert EA, et al. Diurnal cortisol rhythm as a predictor of lung cancer survival. Brain Behav Immun. 2013;30(Suppl):S163-S170.

32. Sephton SE, Sapolsky RM, Kraemer HC, Spiegel D. Diurnal cortisol rhythm as a predictor of breast cancer survival. J Natl Cancer Inst. 2000;92(12):994-1000.
Cancer Management and Research

\section{Publish your work in this journal}

Cancer Management and Research is an international, peer-reviewed open access journal focusing on cancer research and the optimal use of preventative and integrated treatment interventions to achieve improved outcomes, enhanced survival and quality of life for the cancer patient. The manuscript management system is completely online and includes

\section{Dovepress}

a very quick and fair peer-review system, which is all easy to use. Visit http://www.dovepress.com/testimonials.php to read real quotes from published authors. 